\title{
Platelet-rich Fibrin Application in Guided Bone Regeneration Using Autogenous Block Graft in Staged Dental Implant Placement: A Case Report
}

\author{
Manasa D Datla ${ }^{1}$, Burnice NK Chellathurai ${ }^{2}$, Ramakrishnan Thiagarajan ${ }^{3}$, Vijayalakshmi Rajaram ${ }^{4}$
}

\begin{abstract}
Bone has a unique capacity to regenerate itself completely. The major limiting factor is maintenance of space for bone formation. Bone graft materials have been used to facilitate bone formation within a space by occupying the space and allowing subsequent bone growth. Osseous grafting has been shown to be clinically successful in the management of human periodontal defects. Autogenous bone graft is considered as the gold standard for bone regeneration due to its unique properties of osteogenesis, osteoconduction, and osteoinduction. For more predictable regeneration of bone, autografts can be combined with platelet concentrates. This clinical case letter reports a case of Siebert's class I ridge defect which was treated with the staged guided bone regeneration (GBR) approach using autogenous block graft and platelet-rich fibrin (PRF). Keywords: Autograft, Grafting, Implant.

International Journal of Oral Implantology and Clinical Research (2018): 10.5005/jp-journals-10012-1177
\end{abstract}

\section{INTRODUCTION}

The success of the implant surgery depends on three important factors-good initial stability, sufficient amount of bone around the implant, and adequate bone quality. Anterior maxilla is considered as the traumatic zone where the loss of tooth can be due to periodontitis, trauma, and surgery. ${ }^{1}$ Labial deformity of the anterior ridge can be more severe, which compromises the position of the implant.

Several treatment modalities have been described for osseous augmentation which include guided bone regeneration (GBR) with or without particulate bone grafting, ridge splitting, distraction osteogenesis, and grafting of bone blocks harvested intraorally and extraorally. ${ }^{2,3}$

Considering these paradigms, the autogenous bone graft is selected for regeneration of bone due to its host osteoprogenitor cells. It can be procured from intraoral sites such as symphysis or ramus of the mandible, which offers several benefits, such as conventional surgical access and proximity to donor and recipient sites, making it ideal for implant surgery.

Pikos et al. ${ }^{4,5}$ stated that the symphysis provided sufficient bone to augment a deficient ridge by $4-6 \mathrm{~mm}$ in the horizontal dimension and $4 \mathrm{~mm}$ in the vertical dimension, covering a length of a 3-tooth defect. Meijndert et al. ${ }^{6}$ stated that the survival rates for implants placed into sites augmented with chin bone is $100 \%$ and sites augmented with demineralized bone matrix (DMBM) is of $93.5 \%$ with a one-year follow-up.

Choukron et al. ${ }^{7}$ introduced platelet-rich fibrin (PRF), a secondgeneration platelet concentrate that has a synergistic effect on healing process and tissue regeneration of both hard and soft tissues.

The concept of GBR is based on the concept of guided tissue regeneration (GTR), which states that specific cells contribute to the formation of specific tissues. Staged implant placement allows adequate time for complete osseous healing of the site and permits the placement of implants with adequate coverage of hard and soft tissues. $^{8}$

\begin{abstract}
1,2,4 Department of Periodontology, Meenakshi Ammal Dental College, Chennai, Tamil Nadu, India

${ }^{3}$ Department of Periodontology, Adhi Parasakthi Dental College, Chennai, Tamil Nadu, India

Corresponding Author: Burnice NK Chellathurai, Department of Periodontology, Meenakshi Ammal Dental College, Chennai, Tamil Nadu, India, Phone: +91 9790944335, e-mail:dr_burnice@yahoo.co.in How to cite this article: Datla MD, Chellathurai BNK, et al. Platelet-rich Fibrin Application in Guided Bone Regeneration Using Autogenous Block Graft in Staged Dental Implant Placement: A Case Report. Int J Oral Implantol Clin Res 2018;9(1-3):37-41.
\end{abstract}

Source of support: Nil

Conflict of interest: None

This article reports a case in which GBR and staged implant placement was done in \#7 and \#8 regions with autogenous bone graft and composite graft (particulate graft + PRF).

\section{Case Description}

A 24-year-old male reported with the chief complaint of missing right maxillary central and lateral incisor. The patient had a history of trauma followed by avulsion of teeth in the right upper maxillary region and had a noncontributory medical history.

On clinical examination of the recipient site, the gingival biotype was thick with an adequate amount of attached gingiva (Fig. 1). On ridge mapping with bone calipers, the width of the alveolar ridge was about $2.5 \mathrm{~mm}$, indicating horizontal bone loss and inadequate volume of bone for implant placement. Radiographic examination was done for both recipient (Fig. 2) and donor site.

A mandibular symphysis block graft was planned for ridge augmentation in combination with PRF in the anterior maxilla followed by implant placement, after nine months.

() The Author(s). 2018 Open Access This article is distributed under the terms of the Creative Commons Attribution 4.0 International License (https://creativecommons. org/licenses/by-nc/4.0/), which permits unrestricted use, distribution, and non-commercial reproduction in any medium, provided you give appropriate credit to the original author(s) and the source, provide a link to the Creative Commons license, and indicate if changes were made. The Creative Commons Public Domain Dedication waiver (http://creativecommons.org/publicdomain/zero/1.0/) applies to the data made available in this article, unless otherwise stated. 


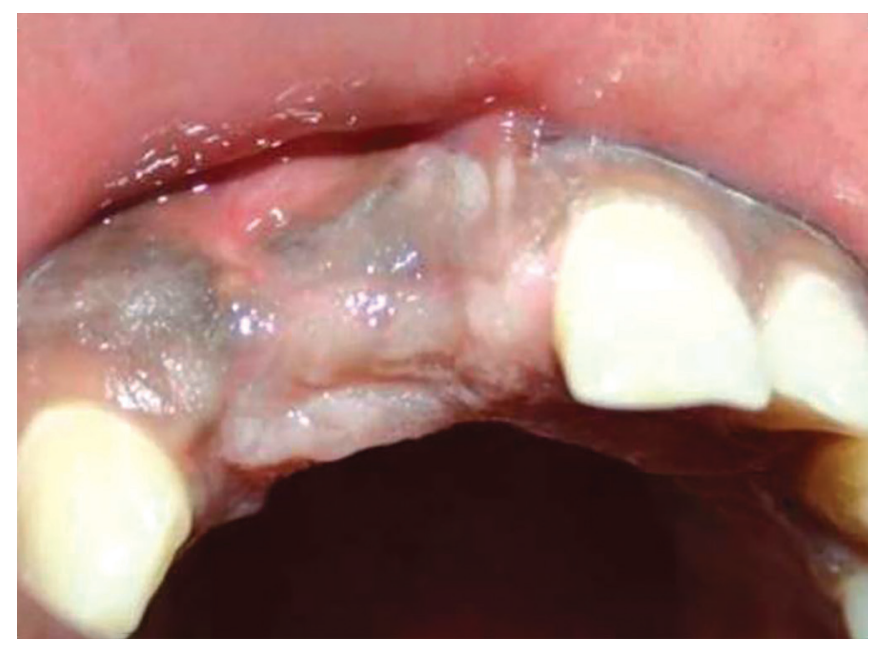

Fig. 1: Preoperative view of the edentulous site in relation to 11 and 12

For the symphysis graft, the periodontal and endodontic health of the mandibular anterior teeth was ascertained. Measurement of the width and thickness of the attached gingiva and depth of the vestibule of lower anterior were made for selecting the appropriate incision design.

\section{Preoperative Preparation}

The patient was started on an oral regimen of amoxicillin $500 \mathrm{mg}$ thrice daily one day prior to surgery to prevent postoperative infection. One hour before surgery, ibuprofen $400 \mathrm{mg}$ was given to prevent postoperative pain.

\section{Surgical Technique}

The patient was instructed to have a preprocedural intraoral rinse of $0.12 \%$ chlorhexidine (Periogard mouth wash, Colgate). Perioral skin preparation was done using povidone-iodine solution $5 \% \mathrm{w} / \mathrm{v}$ (Povidone Solution, Wockhardt).

\section{PRF Preparation}

Ten milliliters of intravenous blood was collected by venipuncture at the antecubital fossa and was transferred into a $10 \mathrm{~mL}$ sterile tube without anticoagulant and centrifuged at about 3,000 rpm for 10 minutes. After coagulation, the fibrin clot present in between the acellular plasma on the top and the red blood cells at the bottom were separated using sterile tweezers and scissors.

\section{Recipient Site Preparation}

Under local anesthesia with $2 \%$ lignocaine hydrochloride with adrenaline bitartrate (Becain-A, Martin \& Brown Bio-Sciences), a crestal incision was given from the mesial of \#6 to the mesial of \#9 with two releasing incisions and mucoperiosteal flap was reflected buccally (Fig. 3).

\section{Donor Site Preparation}

Local anesthesia of $2 \%$ lignocaine was given in relation to lower anterior by the mental nerve block technique, and sulcular incision was given buccally from \#22 to \#27. A mucoperiosteal flap was reflected, relieving the mentalis muscle with periosteum up to the base of the vestibule. Elevation was performed until the mental foramen was located, and inferior border of the mandible was reached. Prior to beginning the osteotomy, the recipient site was remeasured, and measurements were transferred to the symphysis to indicate the desired block size by making notches in the bone

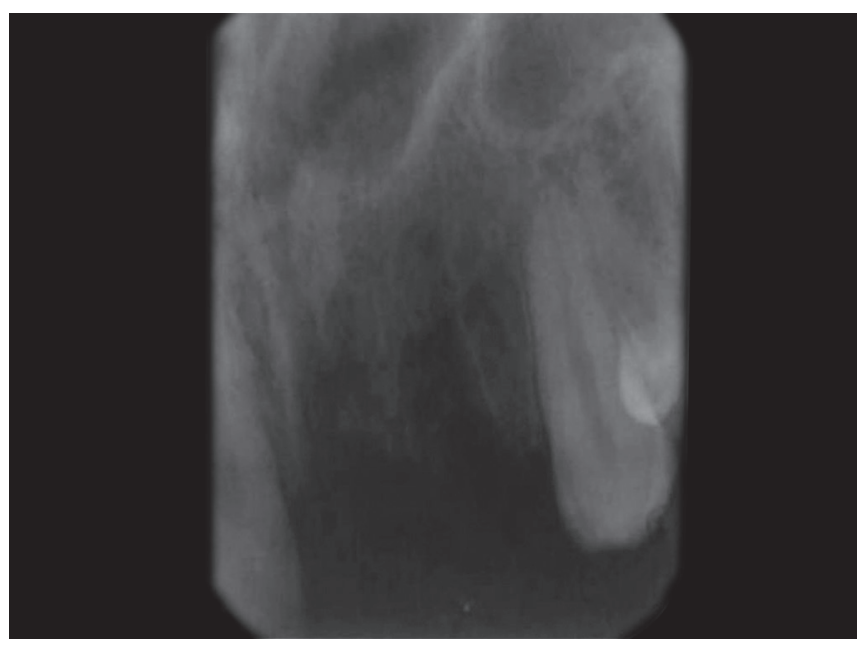

Fig. 2: Preoperative radiographic view of 11 and 12

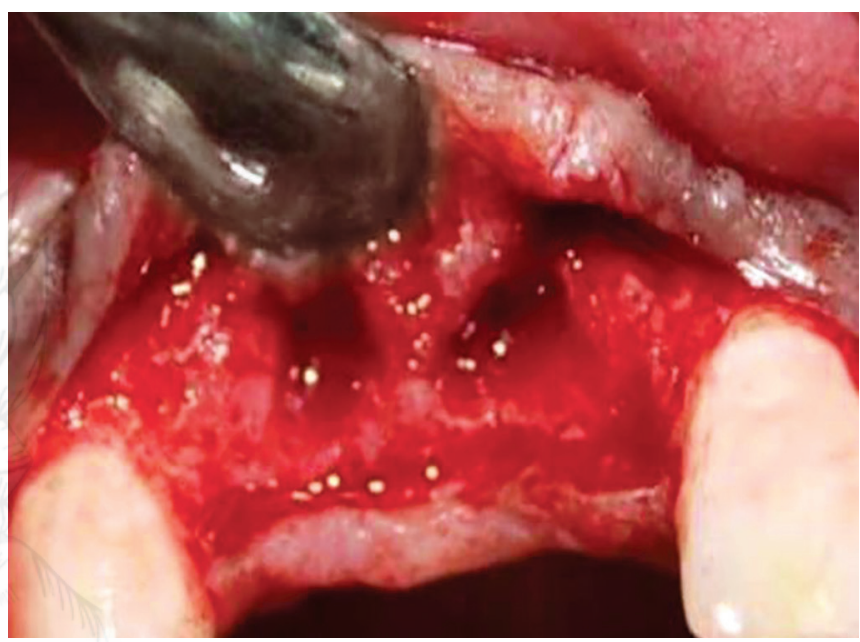

Fig. 3: Flap reflection revealing osseous defect prior to grafting

at the corners of the block outline. Osteotomy was done using a straight fissure carbide bur to outline a rectangle size block graft. For procuring symphysis graft, the "Rule of 5's" was followed with at least $5 \mathrm{~mm}$ of uninvolved bone present beyond the proposed osteotomy margins of the block and the surrounding structures, providing a margin of safety (Fig. 4). ${ }^{9}$ Bone block was removed carefully (Fig. 5) and then the donor site was filled with bone graft DMBM. Closure of the site was done by interrupted sutures using 3-0 silk sutures.

Periodontal dressing was given intraorally on the sutured area. Extraoral pressure dressing (elastic chin-cup) to the symphysis area for 48 hours postoperatively was given to prevent hemorrhage and promote initial healing.

The recipient site was shaped, and sharp bony peaks present were clamped and collected, which was used as particulate graft. The block graft obtained was shaped and adapted to the recipient site. The PRF was prepared and collected in a dappen dish (Fig. 6). The PRF was mixed with the particulate graft and DMBM, making it a composite graft (Fig. 7). The surrounding area of the block was covered with composite graft and stabilized with the help of a titanium screw (Fig. 8). The grafted site was covered with the GTR collagen membrane, and the flap was coronally positioned, and 3-0 black silk sutures were placed (Fig. 9). 


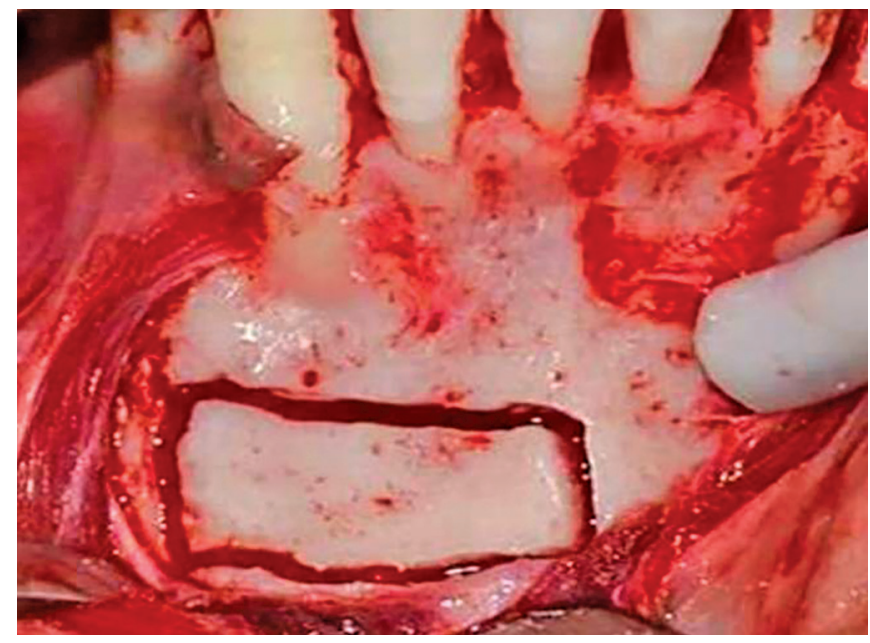

Fig. 4: Outline of block graft from the symphysis region

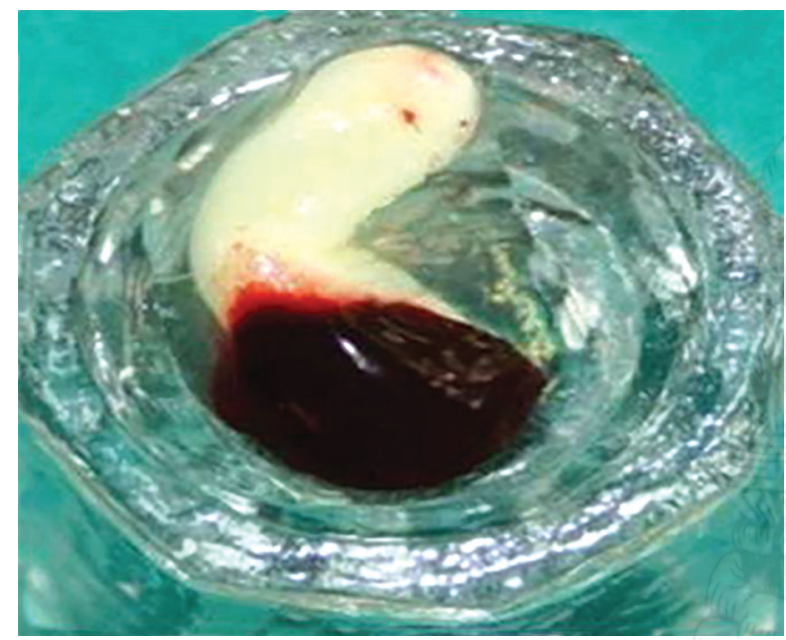

Fig. 6: Platelet-rich fibrin (PRF) gel

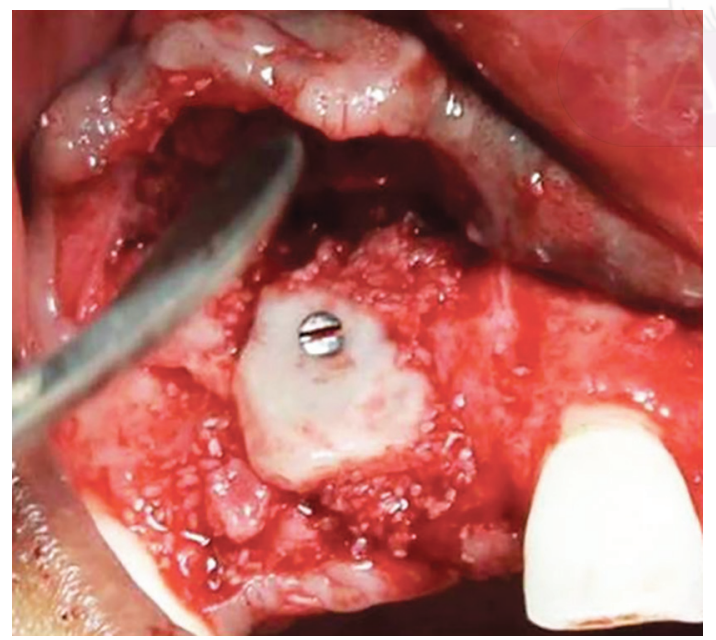

Fig. 8: Block graft stabilized with a titanium screw

\section{Postoperative Care}

The patient was asked to continue antibiotics and analgesics for 5 days. He was advised to rinse his mouth with $0.12 \%$ chlorhexidine gluconate twice daily for a period of 10 days. Oral

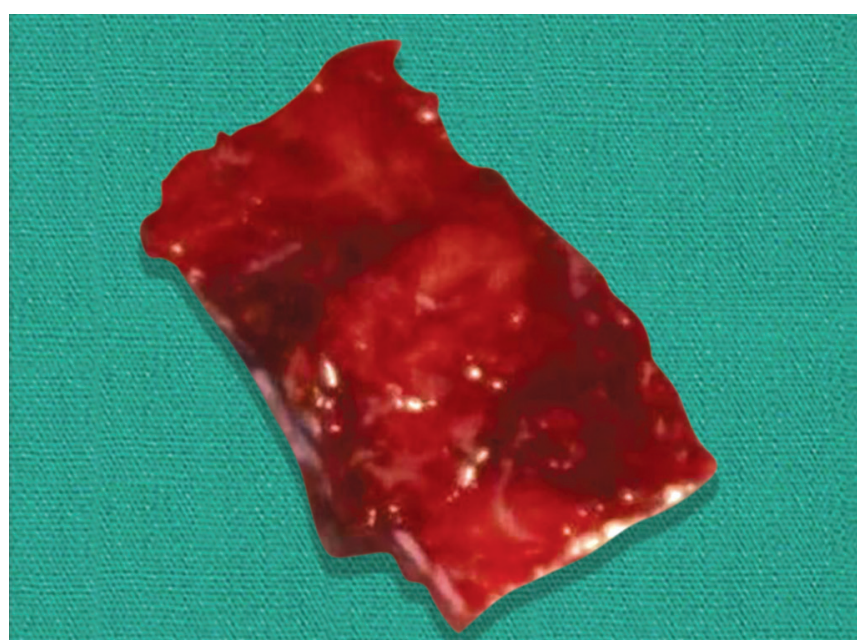

Fig. 5: Autogenous bone block harvested from the symphysial region

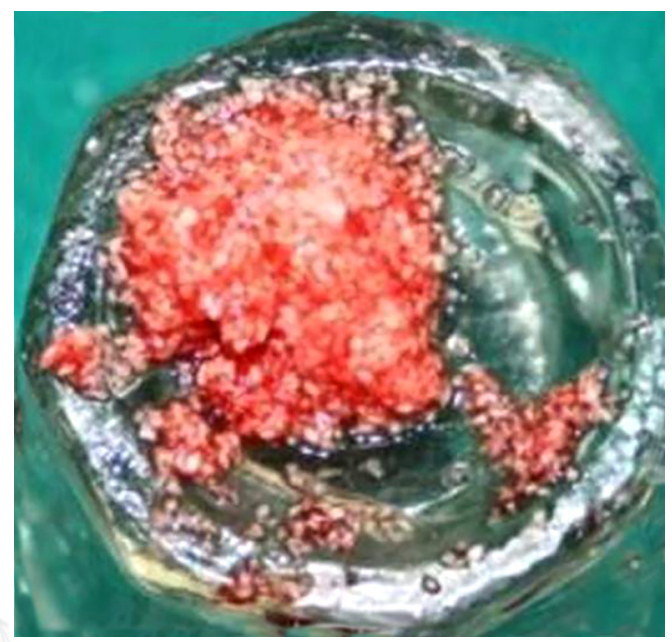

Fig. 7: Composite graft prepared by blending PRF with particulate bone graft obtained from the recipient site

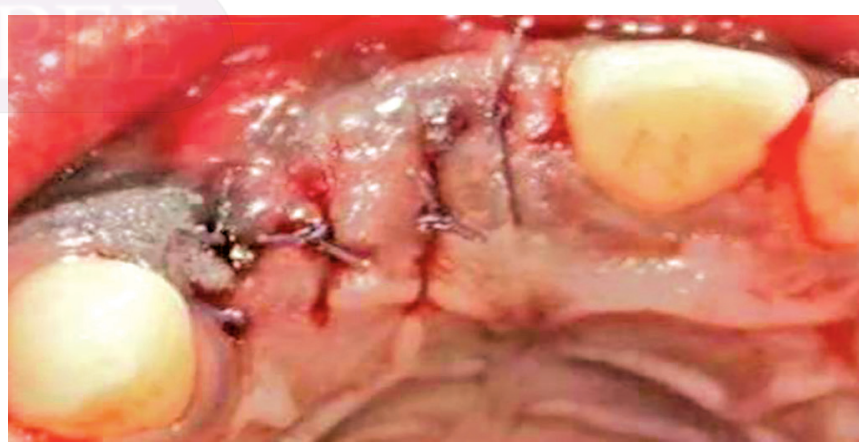

Fig. 9: Approximation of the flap was done using 3-0 black silk sutures

hygiene instructions were reinforced. After two days, the chin cap was removed.

Suture removal was done after two weeks. Healing was found to be satisfactory.

\section{Implant Placement}

After nine months, clinical examination was done in the augmented site (Fig. 10), and radiographic evaluation (Fig. 11) was carried out. Surgical re-entry was done (Fig. 12), the titanium stabilizing screw 


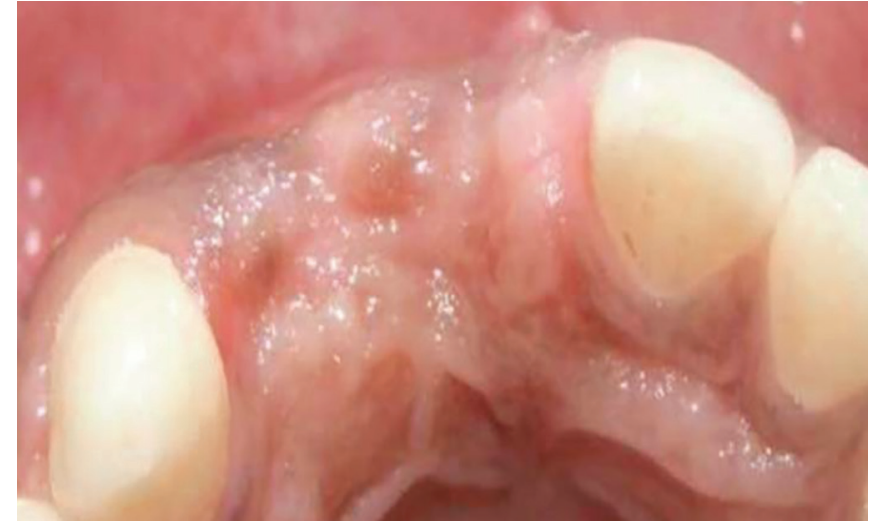

Fig. 10: Postoperative view of the augmented site after 9 months

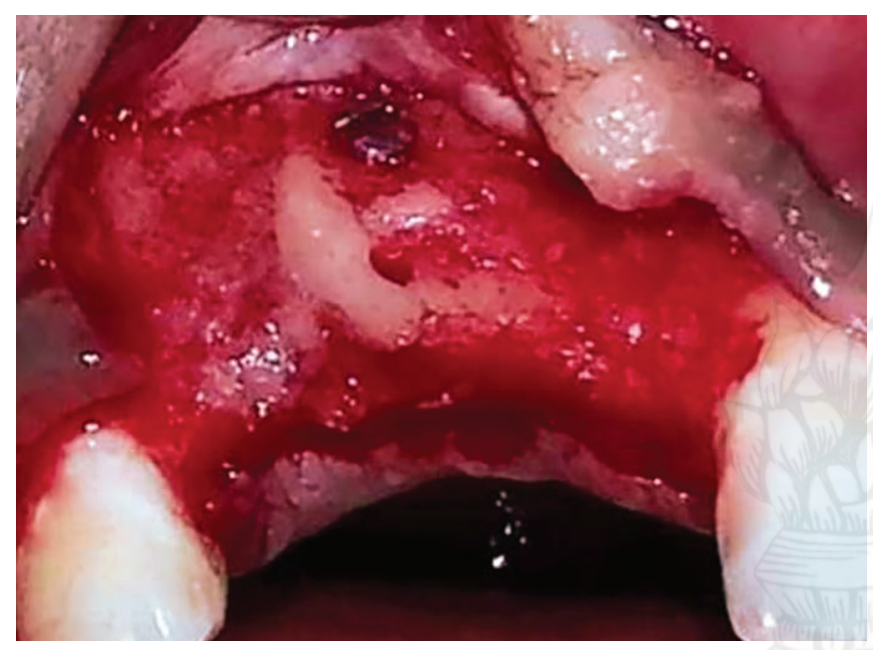

Fig. 12: Surgical reentry after 9 months to remove the titanium screw. An adequate bone fill was observed at the augmented site

was removed, and the available bone was assessed with the help of bone calipers. Horizontal bone width was found to be increased to $5.5 \mathrm{~mm}$ buccolingually. Osteotomy site preparation was done in relation to \#7 and \#8. Endosseous implants of size $3.3 \mathrm{~mm} \times$ $11.5 \mathrm{~mm}$ and $3.3 \times 10 \mathrm{~mm}$ (Alpha Biocare) were inserted in relation to \#7 and \#8, respectively (Fig. 13). Abutment was given for both the implants, 3-0 black silk sutures were placed, and radiographic examination was done (Fig. 14). Immediate restoration was done with provisional acrylic crowns for three months followed by permanent crowns (Fig. 15).

\section{Discussion}

Tooth extraction in the esthetic zone leads to typical and dramatic bone remodeling of the alveolar crest very rapidly, with as much as $50 \%$ loss in width during the first year, two-thirds of which occurring in the initial 3 months. ${ }^{10}$ This extent of hard tissue alteration reduces the quantity of bone available for a subsequent implant placement and impairs the esthetic outcome of prosthodontic rehabilitation.

The advantages of using the block graft harvested from the mandibular symphysis or ramus buccal shelf are:

- Horizontal alveolar bone width increase as documented was up to $7.5 \mathrm{~mm}^{11}$

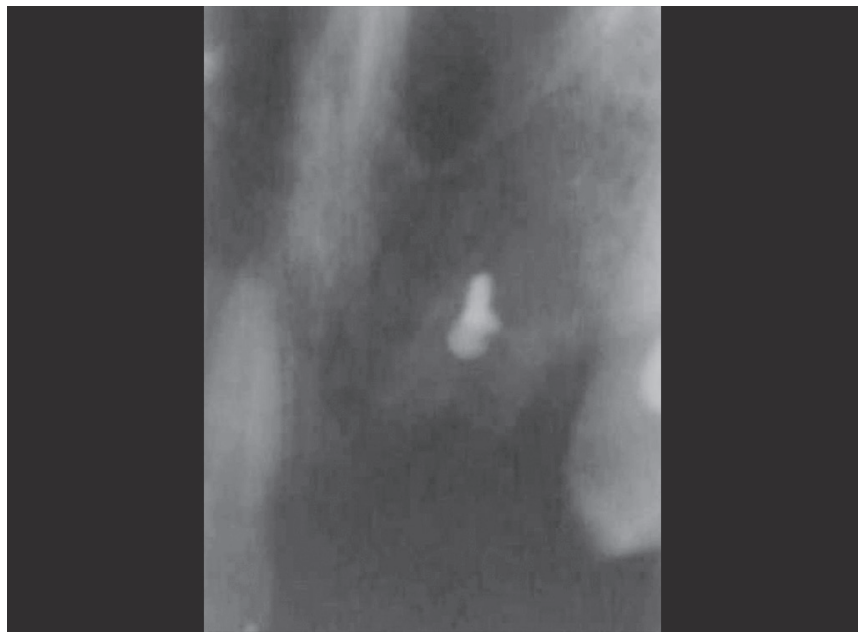

Fig. 11: Postoperative radiograph of the augmented site after 9 months

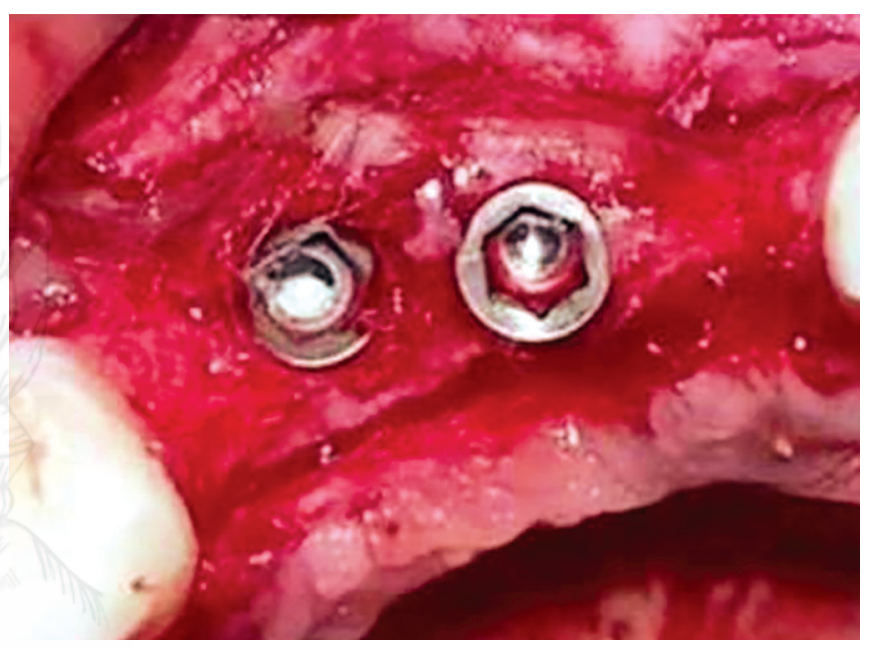

Fig. 13: Internal hex implants placed in relation to 7 and 8

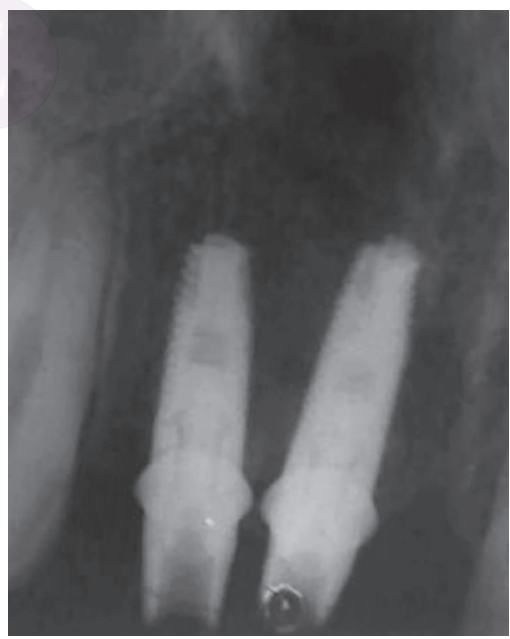

Fig. 14: Postoperative radiographic view of the implants and abutments

- Optimal bone density for implant stability due to the cortical nature of the graft.

- Reliable space maintenance during healing ensures the shape and stability of the bone block without collapse. ${ }^{4}$ 


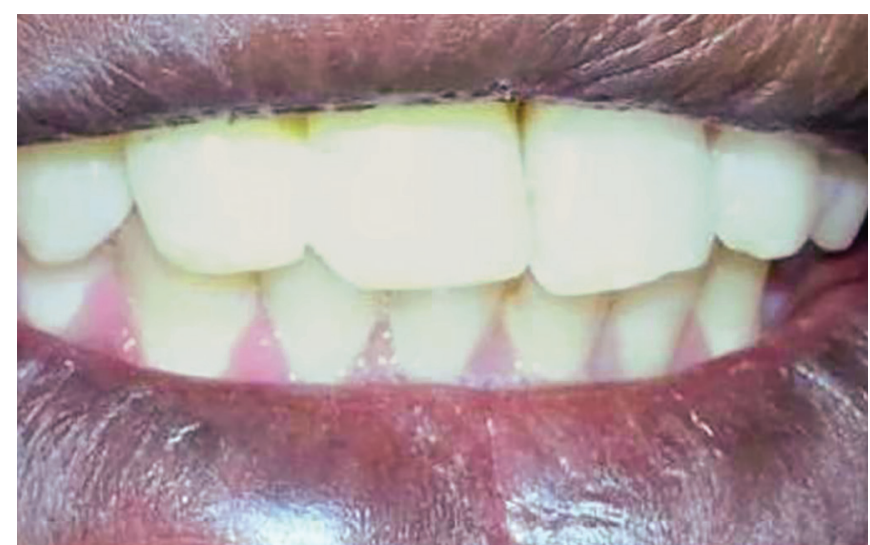

Fig. 15: Permanent restorations were given after 3 months

- Locally available donor sites avoid the need for extraoral bone sources. $^{12}$

Block bone grafts harvested from the symphysis show a predictable outcome in both horizontal and vertical dimensions. The symphysis offers over $50 \%$ larger graft volume than mandibular ramus, with much easier surgical access. The average symphysis graft has been found to be composed of $65 \%$ cortical bone and $36 \%$ cancellous bone. ${ }^{13}$ The corticocancellous nature of the bone harvested from this site facilitates faster vascular in-growth once the block has been placed, resulting in more rapid integration and less potential resorption. ${ }^{14}$

Moreover, bone blocks harvested from sites formed by intramembranous mechanisms have been shown to revascularize faster than those from an endochondrally derived formation pathway. ${ }^{15}$

Though alloplasts have been used for regenerative purposes, most of the time they act as just bone fillers. Autograft along with PRF was used in this particular case, which has contributed to a predictable bone regeneration. Since the autograft was procured from intraoral sites, less resorption of the graft was achieved, and the use of PRF might have released high concentrations of growth factors which have added a synergistic effect.

\section{Conclusion}

This case report demonstrates the efficacy of using a block graft along with PRF, which stimulated the new bone formation and successful placement of dental implant in the augmented site.

\section{References}

1. Evian $\mathrm{Cl}$, Rosenberg ES, et al. The osteogenic activity of bone removed from healing extraction sockets in humans. J Periodontol 1982;53:81-85. DOI: 10.1902/jop.1982.53.2.81.

2. Triplett R, Schow $S$. Autologous bone grafts and endosseous implants: Complementary techniques. J Oral Maxillofac Surg 1996;54:486-494. DOI: 10.1016/S0278-2391(96)90126-3.

3. Tolman D. Reconstructive procedures with endosseous implants in grafted bone: a review of literature. Int J Oral Maxillofac Implants 1995;10:275-294.

4. Pikos MA. Mandibular block autografts for alveolar ridge augmentation. Atlas Oral Maxillofacial SurgClin N Am 2005;13:91-107. DOI: 10.1016/j.cxom.2005.05.003.

5. Schwartz-Arad D, Levin L, etal. Surgical success of intraoral autogenous block onlay bone grafting for alveolar ridge augmentation. Implant Dent 2005;14:131-138. DOI: 10.1097/01.id.0000165031.33190.0d.

6. Meijndert L, Raghoebar GM, et al. Bone quality at the implant site after reconstruction of a local defect of the maxillary anterior ridge with chin bone or deproteinisedcancellous bovine bone. Int J Oral Maxillofac Surg 2005;34:877-884. DOI: 10.1016/j.ijom.2005.04.017.

7. Choukroun J, Diss A, et al. Platelet rich fibrin (PRF): a secondgeneration platelet concentrate. Part V: histologic evaluations of PRF effects on bone allograft maturation in sinus lift. Oral Surg Oral Med Oral Pathol Oral Radiol Endod 2006;101:299-303. DOI: 10.1016/ j.tripleo.2005.07.012.

8. Klokkevold PR. Localized bone augmentation and implant site development. In: Newman MG, Takei HH, et al. ed. Clinical Periodontology, 10th ed., St. Louis: Elsevier Publishing Co Ltd; 2007. pp. 1133-1147.

9. Hunt DR, Jovanovic SA. Autogenous bone harvesting: a chin graft technique for particulate and monocortical bone blocks. Int J Periodontics Restorative Dent 1999;9:165-173.

10. Schropp L. Bone healing and soft tissue contour changes following single-tooth extraction: a clinical and radiographic 12-month prospective study. Int J Periodontics Restorative Dent 2003;23: 313-323.

11. Feuille $\mathrm{F}$, Knapp Cl, et al. Clinical and histologic evaluation of bonereplacement grafts in the treatment of localized alveolar ridge defects. Int J Periodontics Restorative Dent 2003;23:29-35.

12. Linklow LI. Bone transplants using the symphysis, the iliac crest, and synthetic bone materials. J Oral Implantol 1983;11:211-247.

13. Neiva RF, Gapski R, et al. Morphometric analysis of implant-related anatomy in caucasian skulls. J Periodontol 2004;75:1061-1067. DOI: 10.1902/jop.2004.75.8.1061.

14. Hammack BL, Enneking WF. Comparative vascularization of autogenous and homogenous bone transplants. J Bone Joint Surg 1960;42:811. DOI: 10.2106/00004623-196042050-00008.

15. Kusiak JF, Zins JE, et al. The early revascularization of membranous bone. PlastReconstr Surg 1985;76:510-516. DOI: 10.1097/00006534198510000-00003. 